\title{
A ideia de linguagem como formas de vida em documentos linguísticos ${ }^{1}$
}

\section{Language as way of lives in linguistic documents}

\author{
Carlos Alexandre Gonçalves de Jesus ${ }^{2}$ \\ Ana Paula Grillo El-Jaick ${ }^{3}$
}

DOI: https://doi.org/10.34019/2179-3700.2019.v19.29880

\begin{abstract}
Resumo
Este artigo, fruto de uma pesquisa de Iniciação Científica, discute o termo Forma de vida [Lebensform] na obra do filósofo austríaco Ludwig Wittgenstein. Nosso objetivo mais geral foi mapear as ocorrências da expressão na obra do filósofo. Como objetivos específicos, quisemos rever interpretações já consagradas para o termo, com relação ao pensamento wittgensteiniano e, também, pensar outras possíveis vias hermenêuticas. Além disso, visamos entender esse conceito dentro da filosofia de Wittgenstein, principalmente em seu segundo momento. Dado que se trata de pesquisa conceitual, sua metodologia foi fundamentalmente bibliográfica. Nossa discussão se baseou estruturalmente no texto de Araceli Velloso (2003) "Formas de vida ou formas de vida?", artigo resumitivo de sua tese de Doutorado defendida na Pontifícia Universidade Católica do Rio de Janeiro (PUC-Rio). Como resultado/conclusão, terminamos nossas linhas com mais perguntas do que respostas, conforme se espera de uma pesquisa em Filosofia da Linguagem, já que seu objetivo primeiro deve ser sempre o de fomentar o pensamento crítico.

Palavras-chave: L. Wittgenstein. Formas de vida. Investigações Filosóficas.
\end{abstract}

\begin{abstract}
This article discusses the term Lebensform in the work of the Austrian philosopher Ludwig Wittgenstein. Our most general goal was to map the occurrences of this expression in the philosopher's work. As specific objectives, we wanted to revise already well-established interpretations for the term in relation to Wittgensteinian thought, and also to think of other possible hermeneutical paths. In addition, we aim to understand this concept within Wittgenstein's philosophy, especially at its second moment. Given that this is a conceptual research, its methodology was fundamentally bibliographical. Our discussion was structurally based on Araceli Velloso's article "Forms of life or forms of life?", result of her doctoral thesis defended at the Pontifical Catholic University of Rio de Janeiro (PUC-Rio). As a result / conclusion, we end these lines with more questions then answers, as expected from a research in Philosophy of Language, whose prime objective should always be to foster critical thinking.

Keywords:L. Wittgenstein. Way of life. Philosophical Investigations.

\footnotetext{
${ }^{1}$ Trabalho premiado no Seminário de Iniciação Científica da UFJF em 2016.

${ }^{2}$ Bolsista de Iniciação Científica BIC/2015-2016.

${ }^{3}$ Endereço profissional: Universidade Federal de Juiz de Fora, Faculdade de Letras. Campus Universitário, s/n. Cidade Universitária. 36.036-330 - Juiz de Fora / MG. E-mail: anapaulaeljaick@gmail.com
} 
Tudo que pode ser em geral pensado, pode ser pensado claramente. Tudo que se pode enunciar pode-se enunciar claramente.

(L. Wittgenstein, Tractatus Logico-

Philosophicus)

\section{INTRODUÇÃO}

Este artigo destina-se à apresentação de nossa pesquisa de iniciação científica BIC/2015-2016, instalada na Universidade Federal de Juiz de Fora do período de $1^{\circ}$ de setembro de 2015 a 31 de julho de 2016, sob orientação da Profa. Dra. Ana Paula Grillo El-Jaick, do Departamento de Letras desta Universidade.

Com o título A ideia de linguagem como formas de vida em documentos linguísticos, esta pesquisa teve por objetivo geral a investigação do conceito de forma de vida [Lebensform] na obra do filósofo Ludwig Wittgenstein. Ainda que a expressão se apresente de maneira escassa nos textos do autor, pareceu-nos guardar, entretanto, importante significação no conjunto de sua obra. Assim, para mostrar a relevância da expressão, esta pesquisa teve como objetivo geral trazer à luz a ideia de linguagem como forma de vida para os estudos da linguagem, com o intuito de incrementar teoricamente áreas da linguística que compreendem a linguagem como manifestação de uso, ou seja, como práxis.

A partir disso, fez-se necessário circunscrever e investigar o próprio conceito de forma de vida nos textos wittgensteinianos em suas recorrências já consagradas, bem como em momentos que parecem deixar a expressão subentendida. Para isso, foi preciso consultar uma bibliografia secundária, nem sempre unânime no que se refere à interpretação do termo, que pudesse servir de sustentáculo para uma investigação mais segura, coerente, e menos especulativa. Assim, a pertinência do tema para os estudos da linguagem e a autoridade do autor escolhido fizeram com que esta pesquisa se justificasse - e, de fato, fosse contemplada com uma bolsa de Iniciação Científica no referido ano 2015-2016.

\section{METODOLOGIA}

Esta pesquisa foi de cunho essencialmente teórico, de modo que o método não poderia ser senão a visita às principais obras do autor, ou seja, uma análise bibliográfica 
de L. Wittgenstein, na qual mereceu destaque a obra Investigações filosóficas ${ }^{4}$, marca da segunda fase do seu pensamento. Todavia, não seria possível tal leitura sem o auxílio de leituras secundárias complementares de pesquisadores já consagrados e de autoridade reconhecida, que serviram de indicação para o estudo do tema na obra do referido filósofo, bem como se prestaram a pôr à prova hipóteses levantadas por nós ao longo dessa pesquisa.

\section{DISCUSSÃO}

\subsection{Wittgenstein: forma(s) de vida nas Investigações filosóficas}

Considerando o tema da forma de vida como central desta pesquisa, fomos verificá-lo, em primeiro lugar, nas ocorrências das Investigações Filosóficas.Assim, colocamo-nos no pensamento de Wittgenstein de maneira a poder compor um quadro, ainda que genérico, da significação apontada pelo texto, até estarmos preparados para enfrentar as problemáticas que se impõem a uma leitura interpretativa dessa envergadura.

A noção de forma de vida acabou por ser enfeixada a outras expressões wittgensteinianas, como jogos de linguagem, seguimento de regras e semelhanças de famílias, dentre outras, o que permitiu a clarificação da sua noção de linguagem a partir de uma chave de leitura com o próprio conceito de forma de vida.

\subsubsection{Forma de vida: problemáticas e versões}

Um texto que, certamente, se tornou uma baliza para a nossa investigação do tema foi o artigo de Araceli Velloso (2003), intitulado "Formas de vida ou formas de vida?", fruto de sua tese de Doutorado defendida na Pontifícia Universidade Católica do Rio de Janeiro (PUC-Rio). O objetivo principal do artigo é esclarecer a noção de "forma de vida" nos escritos de Wittgenstein, bem como verificar se o emprego da expressão deve ser entendido no singular e/ou no plural. São investigadas ali quatro possíveis interpretações oferecidas por comentadores da obra do filósofo.

Um desses comentadores é Newton Garver (apud VELLOSO 2003). Para ele, trata-se de uma noção menos relevante e, assim, seria um erro procurar um maior esclarecimento sobre ela na obra de Wittgenstein. Afinal, para Garver, "forma de vida" é uma expressão wittgensteiniana propositadamente obscura, sem implicações sérias frente

4 Doravante IF. 
a outras noções do filósofo austríaco. Já outros comentadores, como Norman Malcon, consideram-na uma noção fundamental. Ao mesmo tempo, todos são concordes em considerar que os registros, fontes da expressão, são escassos e de difícil compreensão (exatamente por sua escassez e imprecisão).

Segundo Velloso (2003), a expressão "forma de vida" é de importância central para Wittgenstein, apesar de sua obscuridade. Conforme já foi dito, Velloso coloca que, para começar, há a dificuldade em compreender a expressão em termos de número: devemos entendê-la no singular ou no plural?

A interpretação mais difundida da expressão é feita no plural, mas esta cai em uma armadilha chamada pela autora de "problema do solo comum": se há várias formas de vida distintas, então haveria um conflito radical de comunicabilidade e reconhecimento das formas de vida entre si. Na leitura da expressão no singular não haveria o problema de comunicabilidade, já que todos habitariam a mesma forma de vida; todavia, o problema residiria em como esclarecer quando, em situações especiais, aparecem conflitos radicais.

Velloso (2003), então, desenvolve quatro possíveis interpretações para o termo "forma de vida": "formas de vida" como "jogos de linguagem" (no plural); "formas de vida" como "manifestações orgânicas" (também no plural); "formas de vida" como "culturas diferentes" (igualmente no plural); "forma de vida" como "forma humana" (interpretação singular).

\subsection{2 "Formas de vida" como jogos de linguagem}

Esta interpretação aproxima, de maneira mais ou menos sinônima, as duas expressões wittgensteinianas "Formas de vida" e "Jogos de linguagem". Esta leitura teria pontos positivos na medida em que o termo "jogos de linguagem" é muito melhor trabalhado por Wittgenstein, o que lançaria luz sobre a noção de "Forma de vida".

A passagem clássica a que se referem os comentadores que aproximam os dois conceitos é esta: "[...] representar uma linguagem significa representar-se uma forma de vida" (IF §19). Todavia, como se vê, a comparação recai sobre o termo linguagem - o que não tira o crédito da comparação, já que Wittgenstein, em diversas passagens, considera os jogos de linguagem como linguagens.

Pode-se interpretar os jogos de linguagem de maneira "primitiva" ou "completa". Como exemplo da primeira acepção, Wittgenstein fala da possibilidade de se pensar uma 
linguagem composta apenas de comandos. A segunda forma de ver os jogos (não primitiva) se refere ao todo constituído pela linguagem e por suas ações. Em um terceiro sentido, os "jogos de linguagem" se refeririam às "atividades com as quais ela [a linguagem] está entrelaçada" (IF §7). Esta possível percepção justificaria a ideia de subordinação dos "jogos de linguagem" às atividades que dão origem a ela: "formas de vida".

\subsubsection{A abordagem orgânica}

Segundo M. Hunter (apud VELLOSO 2003), a noção de forma de vida está imbricada a uma forma de vida biológica, na medida em que a linguagem é uma prática comportamental complexa. Assim, falar seria equivalente a comer, andar etc.

A abordagem orgânica possui três características importantes: a ênfase no treinamento, ou no modo como somos engendrados na língua; a aposta em um reflexo fisiológico, de modo que falar seria equiparável a tirar a mão de um objeto quente e; o terceiro aspecto é a "tese da autossuficiência linguística”. Essa última característica se funda no fato de que não precisamos de nenhuma explicação psicológica para entendermos o que uma pessoa diz.

Para Hunter (apud VELLOSO 2003), uma má interpretação da sua teoria seria supor a possibilidade de um mapeamento explicativo e fisiológico do funcionamento dos atos de fala. Além disso, outra objeção possível à sua teoria é que ela exclui o contexto social.

Este, inclusive, é o principal ponto de discordância entre Hunter e outros intérpretes de Wittgenstein, que parecem enfatizar sobremaneira a linguagem como sendo um acontecimento organizado em uma comunidade - como é o caso de Gertrude Conway (apud VELLOSO 2003), que, com seus pares, realça o ato social no lugar da ação do indivíduo. Conway insiste na ideia de uma linguagem não privada pelo pressuposto em se ter que "seguir uma regra", e esta regra só poder ser entendida se for compartilhada entre os falantes. Desse modo, para Conway, não é possível "seguir a regra" particularmente, pois, se assim fosse, não haveria parâmetros para se decidir o que é regra. Contudo, Hunter entende que é exatamente a falta de parâmetros que levaria o indivíduo a buscar um consenso fora dele. Segundo Hunter, a falta de critérios coletivos não implicaria em ter que se buscar critérios particulares, mas em que não é necessário nenhum parâmetro (ou regra) interno ou externo, já que a linguagem residiria no indivíduo como uma reação 
natural. Para defender seu ponto de vista, Hunter se vale da seguinte passagem de Wittgenstein: "Quando obedeço a uma regra eu não tenho escolha. Eu obedeço à regra cegamente" (IF §219).Hunter entende "seguir a regra", a partir desta passagem, como algum tipo de habilidade orgânica. Dessa maneira, a posição de Hunter é uma possível leitura de como se entender a expressão "Forma de Vida" em um contexto praxiológico.

\subsection{4 "Formas de vida" como culturas diferentes}

Nesta interpretação, descrever uma forma de vida seria descrever uma cultura. Assim sendo, seria possível falar em inúmeras formas de vida. Autores como Peter Winch e Vernon Pratt (apud VELLOSO 2003) defendem esta posição. Eles analisam diferentes modos como podemos abordar uma cultura estrangeira diversa da nossa. O foco da discussão, portanto, está na maneira como - fazendo-se uso da antropologia - avalia-se esta outra cultura. Segundo Winch, a dificuldade maior residiria em estabelecer uma racionalidade com padrões diferentes sem abandonar o ponto de vista do avaliador.

Winch, para resolver este desafio, se sustenta na ideia de uma racionalidade que seria condição de possibilidade para qualquer linguagem. Seria uma espécie de "solo comum" através do qual poder-se-ia compreender outras culturas, já que todas possuiriam algum critério de racionalidade. Para ele, esta racionalidade se sustenta no fato de que a vida teria um sentido comum a todos os seres vivos, "um sentido de significância da vida humana" (WINCH apud VELLOSO, 2003, p. 173). Assim, poderiam ser encontrados princípios aceitos por todos, que garantiriam uma regularidade e unidade que se manifestariam na maneira como diferentes culturas convivem. Segundo ele, isto possibilitaria traçar ema relação entre a concepção de racionalidade da cultura que se analisa e a própria cultura do pesquisador.

A objeção que a autora do artigo faz é se o solo comum, encontrado por Winch, não estaria dando lugar ao conceito de "forma de vida"; dessa forma, todos os problemas relativos a este poderiam ser facilmente aplicados àquele. Afinal, "como reconhecer que outras pessoas têm um 'senso' de significância da vida humana diferente do nosso, se temos pontos de vista diferentes?" (VELLOSO, 2003, p. 174-175).

\subsubsection{A interpretação "singular"}

O principal defensor dessa interpretação singular é Newton Garver (apud VELLOSO 2003), que sugere, como única interpretação plausível, que a expressão 
"Forma de vida" se refere a uma única forma de vida, a saber, a forma de vida humana. Ele se apoia nas ocorrências que estão no singular, ainda que faça referência às outras ocorrências presentes na obra de Wittgenstein, não somente nas Investigações Filosóficas.

Garver (apud VELLOSO 2003) sustenta sua interpretação por meio de um apoio textual e de um argumento geral. Ele acredita que ou as pessoas leram erradamente a expressão, colocando-a no plural, ou existe pelo menos uma versão da passagem no plural. Segundo o argumento geral, de cunho filosófico, Garver afirma que é coerente falar de uma única forma de vida, posto que a linguagem é um elemento comum aos seres humanos.

Para Garver (apud VELLOSO 2003), o problema de se interpretar o termo no plural se põe ao se crer que qualquer composição seja uma linguagem. Ele entende que uma linguagem é aquela que tem o seu uso dependente de algum tipo de ser vivo. Segundo Garver, ao interpretar o já citado aforismo 19 das Investigações Filosóficas ${ }^{5}$ de modo pluralista, estar-se-ia "cometendo um erro lógico ao afirmar que da premissa: quando eu imagino uma linguagem eu imagino uma forma de vida, [...] se siga que quando eu imagino duas linguagens eu imagino duas formas de vida" (GARVER apud VELLOSO, 2003, p. 177). Para Garver, a forma de vida é a humana - e envolve todos os fenômenos descritos por Wittgenstein no conhecido aforismo 23 das Investigações Filosóficas, como dar ordens, perguntar, contar, nomear etc.

\section{RESULTADOS E CONCLUSÃO}

À guisa de "conclusão", passo a elencar algumas observações e perguntas que resultaram de minha pesquisa bibliográfica do campo da filosofia da linguagem - campo este que não propriamente espera uma conclusão última, mas cuja expectativa primeira é produzir pensamento crítico:

1. O filosofar é um jogo de linguagem;

2. Há uma fetichização da incomunicabilidade nos estudos linguísticos ditos "pósmodernos";

3. A "ponte comum" que Velloso procura no texto dela só poderia se dar, a seguirmos o primado wittgensteiniano de filosofar, pela concepção de semelhança de família;

5 "[...] representar uma linguagem significa representar-se uma forma de vida" (IF §19). 
4. A perspectiva de linguagem de Wittgenstein não pode ser acusada de pragmática no sentido radical - o uso não pode ser "metafísico", senão, qualquer uso poderia ser válido;

5. A partir das hipóteses levantadas por Velloso, o que se conclui é que não podemos mesmo definir aprioristicamente a expressão "forma de vida". Antes, devemos usar a expressão - e uma interpretação não deve ser preferida em detrimento a outra;

6. O sujeito em Wittgenstein pode ser pensado assim: o sujeito determina a linguagem, mas a linguagem também determina o sujeito;

7. Nossa certeza está em nossa forma de vida - no agir,

8. A interpretação de forma de vida como vida humana (no singular) não leva em conta o fato de que somos (humanos) singulares e plurais - somos diferentes. Logo, a vida humana também compreende o que se está chamando de cultural;

9. A comunidade que o cético pirrônico segue seria uma forma de vida?;

10. A "necessidade antropológica" de que fala o filósofo wittgensteiniano $S$. Cavell se aproximaria da concepção de forma de vida?;

11. A linguagem não é metafísica; prova disso é que não basta irmos ao dicionário para sabermos como usá-la - exatamente porque ela é forma de vida.

Conforme preveni, como uma autêntica pesquisa em Filosofia da Linguagem, termino este artigo assim: com perguntas, mimetizando a pesquisa filosófica, que sempre repõe questões.

\section{REFERÊNCIAS}

BARBOSA FILHO, B. Nota sobre o conceito de jogo-de-linguagem nas 'Investigações' de Wittgenstein. ITA-Humanidades, Porto Alegre, v. 9, p. 75-104, 1973.

GLOCK, H-J. Dicionário Wittgenstein. Tradução: Helena Martins. Revisão técnica: Luiz Carlos Pereira. Rio de Janeiro: Ed. Jorge Zahar, 1998.

LITAIFF, Aldo; NEVES, Cristiano. Repensar a linguagem: Wittgenstein e Davidson contra o representacionismo. Crítica Cultural, Santa Catarina, v. 4, n. 2,p,9-22, 2009.

MARCONDES, D. Wittgenstein: linguagem e realidade.Caderno de pedagogia e cultura, Niterói, v. 3, n. 2, p. 217-230, jul./dez. 1994.

MARTELOTTA, Mário Eduardo (org.).Manual de linguística. São Paulo: Contexto, 2008.

MARTINS, H. Sobre a estabilidade do significado em Wittgenstein. Veredas - revista de estudos linguísticos Universidade Federal de Juiz de Fora, Juiz de Fora, v. 4, n. 2., p.1942, jul/dez 2000. 
MUSSALIM, Fernanda; BENTES, Anna Cristina (org.). Introdução à Linguística: domínios e fronteiras. 5. ed. São Paulo: Cortez, 2006.

PEREIRA, Luiz Carlos. Algumas considerações sobre o conceito de sujeito no Tractatus de Wittgenstein.Analítica, Rio de Janeiro, v. 1, n. 1, p. 193-152, 1993.

PINTO, Paulo Roberto Margutti. A questão do sujeito transcendental em Wittgenstein.In: p. 9-58. Wittgenstein. Ética - Estética - Epistemologia. Campinas: Unicamp/CLE, 2006.

SANTOS, L. H. L. dos. A harmonia essencial. In: NOVAES, Adauto (org.). A crise da razão. São Paulo: Companhia das Letras, 1996. p. 437-455.

VELLOSO, Araceli. Forma de vida ou formas de vida? Philósophos, Goiânia, v. 8, n. 2, p. 159-184, jul./dez. 2003.

WITTGENSTEIN, L. TractatusLogico-Philosophicus. Tradução, apresentação e estudo introdutório: Luiz Henrique Lopes dos Santos. Introdução de Bertrand Russell. 3. ed. São Paulo: Editora da Universidade de São Paulo, 2001.

. Cultura e valor. Lisboa: Edições 70, 2000.

. Filosofia. Tradução: Antônio Zilhão. Manuscrito São Paulo: Unicamp, , v. XVIII, n. 2, p.1-37out. 1995.

Investigações Filosóficas. Tradução: José Carlos Bruni. São Paulo: Abril

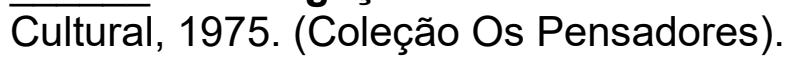

